\title{
Agonist-specificity in the role of $\mathrm{Ca}^{2+}$-induced $\mathrm{Ca}^{2+}$ release in hepatocyte $\mathrm{Ca}^{2+}$ oscillations
}

\author{
Antonio SANCHEZ-BUENO* and Peter H. COBBOLD $\dagger$ \\ Department of Human Anatomy and Cell Biology, University of Liverpool, P.0. Box 147, Liverpool L69 3BX, U.K.
}

$\mathrm{Ca}^{2+}$-mobilizing hormones induce oscillations in the cytoplasmic concentration of free $\mathrm{Ca}^{2+}$ ('free Ca') (spikes) in many cells. In hepatocytes the frequency of spiking depends on agonist dose, but the time course of an individual spike does not change with agonist concentration. Interestingly, the time course of individual spikes does depend on the hormone species, but the cellular mechanisms underlying this agonist-specificity are not understood. Here we show that ryanodine, which blocks the muscle $\mathrm{Ca}^{2+}$ channel responsible for $\mathrm{Ca}^{2+}$-induced $\mathrm{Ca}^{2+}$ release (' $\mathrm{CICR}$ ') in the open conformation, has almost no effect on phenylephrineinduced spikes, but does, in contrast, inhibit vasopressin- or angiotensin II-induced spikes. We also show that ryanodine has no effect either on the increase in frequency or on the elevated peak free $\mathrm{Ca}$ induced by increased cyclic AMP on phenylephrine spikes. In contrast, ryanodine truncates the prolonged falling phases of spikes induced by vasopressin or angiotensin II in the presence of elevated cyclic AMP. A working hypothesis is proposed in which vasopressin- or angiotensin II-induced spikes consist of an Ins $(1,4,5) P_{3}$-mediated symmetrical spike, identical in time course and mechanism with those induced by phenylephrine, followed by a 'tail' that represents CICR. The data hint at the existence of a novel signalling pathway.

\section{INTRODUCTION}

$\mathrm{Ca}^{2+}$-mobilizing agonists such as phenylephrine and vasopressin, which are mediated by $\operatorname{Ins}(1,4,5) P_{3}$, induce oscillations in cytoplasmic concentration of free $\mathrm{Ca}^{2+}$ ('free $\mathrm{Ca}$ ') in single rat hepatocytes [1,2]. Although the frequency of the oscillations depends on agonist dose, the time course of an individual spike does not change with agonist concentration. A spike's time course does, however, depend on the agonist species. Although the rise time and amplitude do not change with the agonist, the falling time, and hence the spike duration, is markedly dependent on the type of the agonist, in the same individual hepatocyte [1-5]. This agonist-specificity in the oscillator mechanisms has yet to be explained.

Studies with permeabilized hepatocytes have shown that a maximal dose of Ins $(1,4,5) P_{3}$ releases only a part of the $\mathrm{Ca}^{2+}$ stored in the non-mitochondrial pool: the residual $\mathrm{Ca}^{2+}$ can be released by $\mathrm{Ca}^{2+}$ ionophores [6,7]. These data suggest that the Ins $(1,4,5) P_{3}$-insensitive pool is a separate membrane-limited compartment. Ryanodine, a plant alkaloid which locks the sarcoplasmic-reticulum $\mathrm{Ca}^{2+}$ channel in the open state [8-10], blocks Ins $(1,4,5) P_{3}$-independent free $\mathrm{Ca}$ oscillations in several cell types $[11,12]$; thus blockade by ryanodine provides evidence for a $\mathrm{Ca}^{2+}$-induced $\mathrm{Ca}^{2+}$ release (CICR) mechanism [11,13]. Recently high-affinity ryanodine-binding sites have been found in rat liver microsomes [14]. The ryanodine-binding sites were distinct from Ins $(1,4,5) P_{3}$-binding sites and had different distributions between the various sub-microsomal fractions [15].

Here we show that ryanodine fails to modify phenylephrineinduced spikes (as previously described in outline [5]), but does inhibit spikes induced by vasopressin or angiotensin II. Furthermore, ryanodine can truncate the falling phase of vasopressin- or angiotensin II-induced spikes prolonged by elevated cyclic AMP [16]. We propose that vasopressin- or angiotensin- induced spikes consist of an $\operatorname{Ins}(1,4,5) P_{3}$-mediated symmetrical spike, similar in time course and mechanism to those induced by phenylephrine, followed by a 'tail' that represents CICR. These data raise the question why ryanodine-sensitivity should occur only in vasopressin- or angiotensin-treated cells, and why the Ins $(1,4,5) P_{3}$-mediated component of the spikes induced by these peptides is abolished by ryanodine.

\section{MATERIALS AND METHODS}

Single hepatocytes from fed male Wistar-strain rats (180-250 g) were isolated and injected with the photoprotein aequorin as described previously [17], and the free Ca changes were recorded by photomultiplier. The experimental medium was William's Medium E (Flow Laboratories) gassed with $\mathrm{CO}_{2} /$ air $(1: 19)$ at $37^{\circ} \mathrm{C}$. All substances were added to this medium. Phenylephrine, vasopressin, angiotensin II and dibutyryl cyclic AMP were from Sigma, and ryanodine was from Calbiochem.

\section{RESULTS}

We carried out experiments using ryanodine, a well-known blocker of the CICR mechanism in those cell types where this mechanism is responsible for generating free $\mathrm{Ca}$ oscillations [13]. Figure 1(a) shows that ryanodine $(1,10$ or $100 \mu \mathrm{M})$ did not produce any significant change on phenylephrine-induced spikes over periods of exposure of 10-60 min (seven out of ten hepatocytes). Similar absence of effect of ryanodine on phenylephrineinduced spikes has been found in single hepatocytes loaded with Fura-2 [18]. In hepatocytes 8 and 9, a slight decrease in phenylephrine-induced spiking frequency was found at ryanodine concentrations of 10 and $50 \mu \mathrm{M}$ respectively (results not shown). In hepatocyte 10, phenylephrine-induced spiking was blocked by $10 \mu \mathrm{M}$ ryanodine (results not shown). Exposure of one hepato-

\footnotetext{
Abbreviations used: free $\mathrm{Ca}$, cytoplasmic concentration of free $\mathrm{Ca}^{2+} ; \mathrm{ClCR}, \mathrm{Ca}^{2+}$-induced $\mathrm{Ca}^{2+}$ release

* Present address: Centro de Investigaciones Biomedicas, CSIC, Arturo Dupeerier 4, 28029 Madrid, Spain.

$\dagger$ To whom correspondence should be addressed.
} 


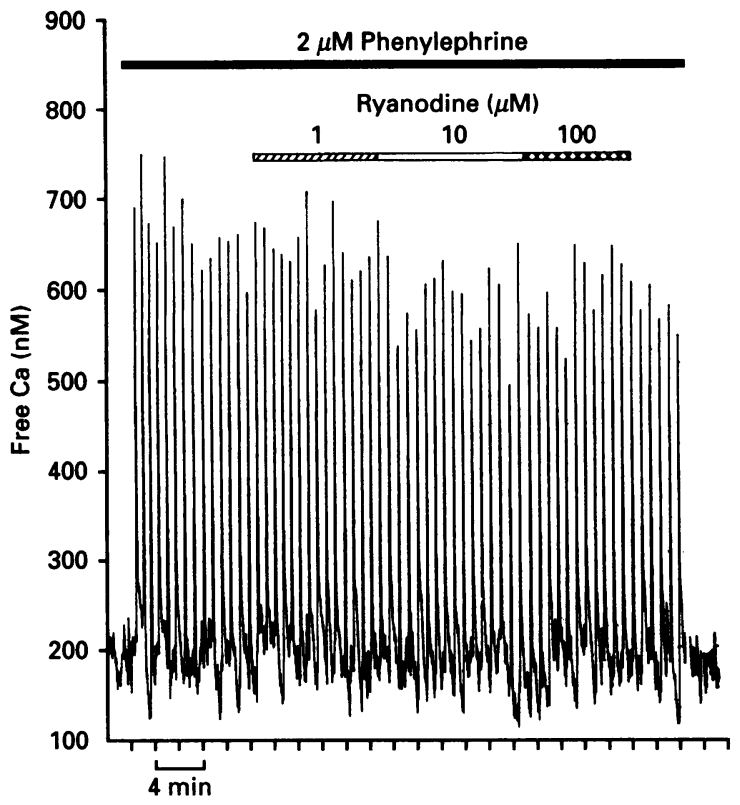

Figure 1 Free Ca spikes induced by $2 \mu \mathrm{M}$ phenylephrine in an aequorinInjected hepatocyte are resistant to blockade by ryanodine $(1,10,100 \mu \mathrm{M})$

Time constants in all Figures are $1 \mathrm{~s}$ for spikes, and $10 \mathrm{~s}$ for resting signals.

cyte to $100 \mu \mathrm{M}$ ryanodine for $20 \mathrm{~min}$ had no effect on free $\mathrm{Ca}$, nor did it have any effect on subsequent phenylephrine-induced spikes (results not shown).

The effect of ryanodine on vasopressin-induced spiking is markedly different. Figure 2(a) shows that $10 \mu \mathrm{M}$ ryanodine promptly and irreversibly blocked vasopressin spikes. This result was found in seven out of 14 hepatocytes stimulated with vasopressin and treated with ryanodine at concentrations from 1 to $30 \mu \mathrm{M}$. In five of the remaining seven hepatocytes, ryanodine, in the same concentration range, irreversibly decreased the frequency of vasopressin-induced spikes (results not shown). In hepatocyte 13 , ryanodine did not produce any significant change in vasopressin-induced free $\mathrm{Ca}$ oscillations, even at concentrations of $50 \mu \mathrm{M}$ (results not shown), and in hepatocyte 14 , $10 \mu \mathrm{M}$ ryanodine decreased the peak free $\mathrm{Ca}$ of oscillations induced by vasopressin (results not shown).

Figure 2(b) shows that ryanodine irreversibly decreased the frequency and slightly decreased the peak free $\mathrm{Ca}$ of spikes induced by $0.5 \mathrm{nM}$ angiotensin II. This effect was ryanodinedose-dependent and was found in three out of five hepatocytes stimulated with angiotensin II and treated with ryanodine. In one of these three hepatocytes, ryanodine decreased the frequency of angiotensin II-induced spikes without any effect on peak free $\mathrm{Ca}$ (results not shown). In the fourth and fifth hepatocytes, ryanodine $(1-5 \mu \mathrm{M})$ irreversibly stopped the spikes induced by angiotensin II (results not shown) in a manner resembling that shown in Figure 2(a).

Dibutyryl cyclic AMP increases the frequency and peak free $\mathrm{Ca}$ of spikes induced by phenylephrine [16]. Figure 3(a) shows this response and also shows that ryanodine has no significant effect on either frequency or peak free $\mathrm{Ca}$ of spikes induced by phenylephrine and elevated cyclic AMP (five hepatocytes). Low concentrations of cyclic AMP prolong the falling phase of vasopressin-induced spikes [16]. Figure 3(b) shows that $2 \mu \mathrm{M}$ ryanodine shortened the falling phase of the prolonged spikes
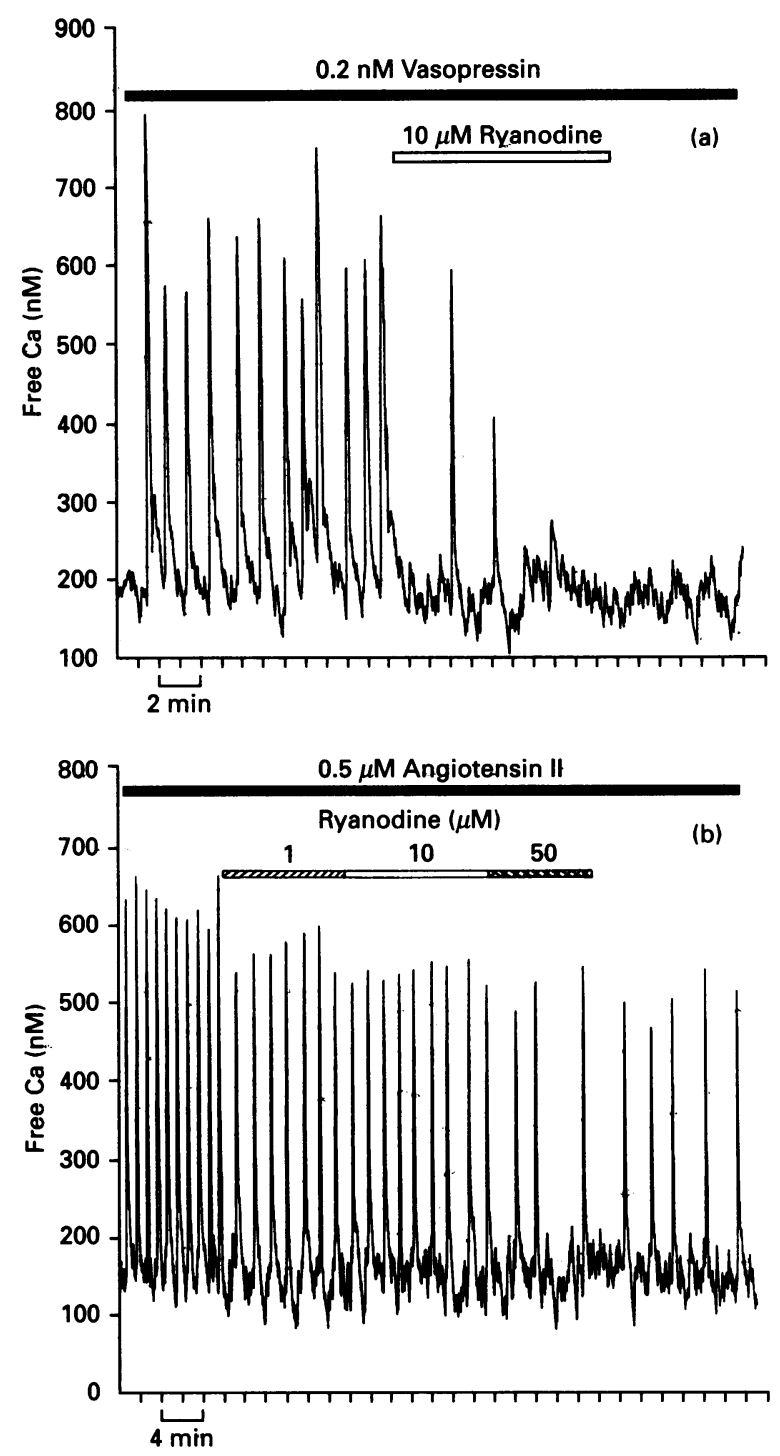

Figure 2 (a) Free Ca spikes induced by $0.2 \mathrm{nM}$ vasopressin are blocked Irreversibly by $10 \mu \mathrm{M}$ ryanodine; (b) splkes. induced by $0.5 \mathrm{nM}$ angiotensin II are irreversibly slowed in their frequency by ryanodine (1-50 $\mu \mathrm{M})$

induced by $0.2 \mathrm{nM}$ vasopressin in conjunction with $1 \mu \mathrm{M}$ dibutyryl cyclic AMP. This shortening is pronounced on the first two spikes after addition of ryanodine, and then the spikes' tails become more prolonged, but without reaching the prolongation observed before ryanodine was added (Figure $3 \mathrm{~b}$ ). When the ryanodine concentration was increased (up to $20 \mu \mathrm{M}$ ), the same result was found: the first two free $\mathrm{Ca}$ spikes were faster on their falling phase than subsequently (results not shown). Broadly similar results were found when cells exposed to angiotensin II and elevated cyclic AMP were presented with ryanodine.

The question arises, of course, as to whether ryanodine interferes directly with vasopressin-receptor function. We are grateful for the unpublished work of L. L. T. Dasso and C. W. Taylor, who have shown, by measuring, as previously $[19,20]$, $\left[{ }^{3} \mathrm{H}\right]$ vasopressin binding to hepatocyte membranes in the absence or presence of $100 \mu \mathrm{M}$ guanosine $5^{\prime}-[\gamma$-thio]triphosphate, that $10 \mu \mathrm{M}$ ryanodine had no significant effect on vasopressin binding (all binding levels in the presence of ryanodine were within 2\% of control values). Likewise, ryanodine had no effect on $\alpha_{1}$ adrenergic receptors, monitored by $\left[{ }^{3} \mathrm{H}\right]$ prazosin displacement by 

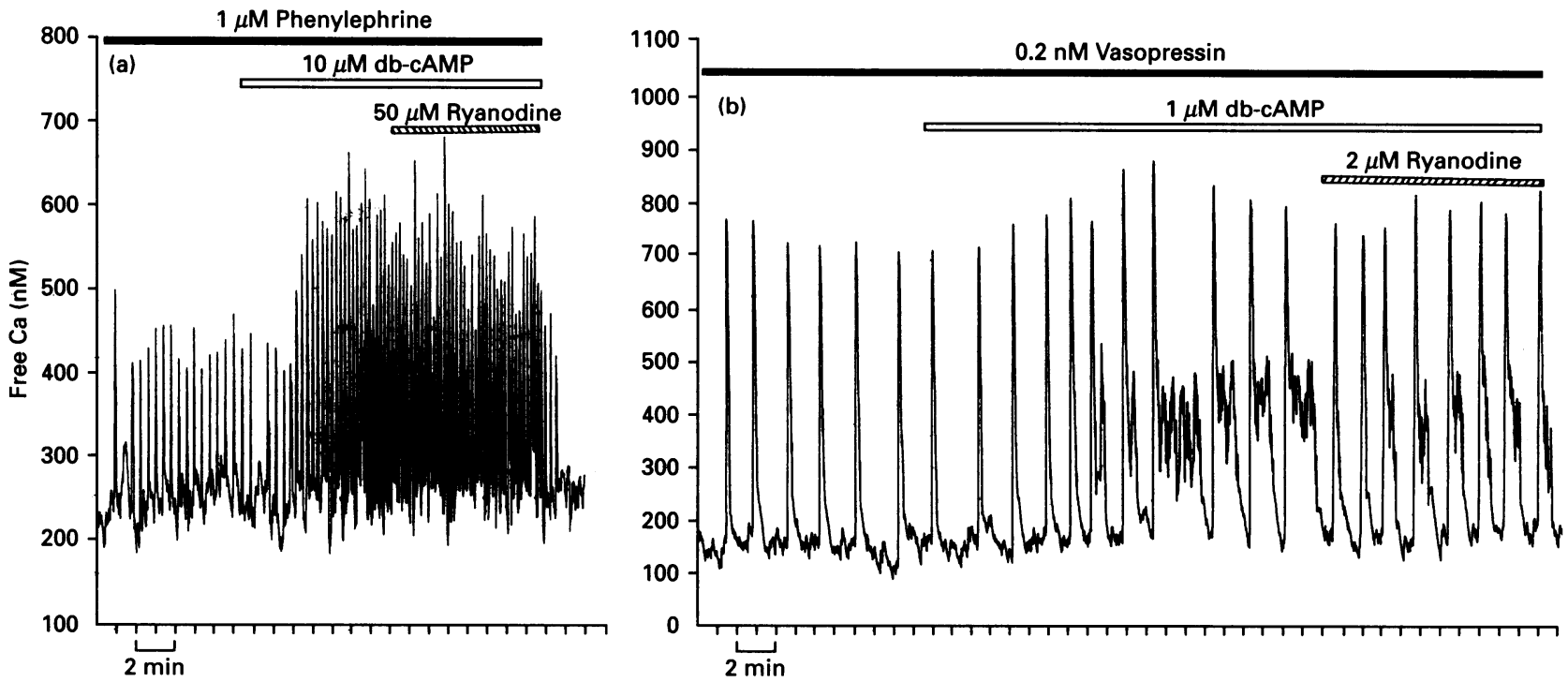

Figure 3 (a) Elevated cytoplasmic cyclic AMP, induced by $10 \mu \mathrm{M}$ dibutyryl cyclic AMP (db-cAMP), increases the peak height and frequency of spiking Induced by $1 \mu \mathrm{M}$ phenylephrine; (b) elevated cyclic AMP, induced by $1 \mu \mathrm{M}$ dibutyryl cyclic AMP, prolongs the talls of vasopressin-induced spikes

In (a), ryanodine $(50 \mu \mathrm{M})$ subsequently has no effect. In (b), ryanodine $(2 \mu \mathrm{M})$ promptly truncated the tails, particularly for the first two or three spikes.

phenylephrine. So ryanodine $(10 \mu \mathrm{M})$ affects neither agonist binding nor, probably, interaction of these receptors with their G-protein(s). Evidence is emerging that these two receptors may communicate with a common pool of G-proteins [20], and it is therefore unlikely that the different ryanodine sensitivity of vasopressin and phenylephrine $\mathrm{Ca}$ spiking arises before Ins $P_{3}$ generation.

\section{DISCUSSION}

The evidence suggests that CICR mediated by a muscle-like ryanodine receptor plays no role in hepatocyte $\mathrm{Ca}$ oscillations induced by phenylephrine. Ryanodine almost certainly enters hepatocytes rapidly; its rapid blockade of $\mathrm{Ca}$ oscillations in myocytes [5], and prompt effects on vasopressin-induced spiking (Figures 2 and 3 ) both point to rapid ryanodine entry into cells. So the lack of effect of ryanodine on phenylephrine-induced spiking (Figure $1 ;[5,18]$ ) almost certainly reflects a lack of importance of CICR mediated by the ryanodine receptor in phenylephrine-induced spiking. Hepatocytes do show intracellular, high-affinity and specific ryanodine-binding sites [14], which appear to be predominantly in a different microsomal fraction from that enriched with Ins $P_{3}$-binding sites [15]. So, presumably, in phenylephrine-stimulated cells either the ryanodine receptors are somehow inactivated, or their compartment has insufficient luminal $\mathrm{Ca}^{2+}$ to permit CICR. We conclude, as have others [18], that CICR mediated by the ryanodine receptor plays no role in phenylephrine-induced $\mathrm{Ca}^{2+}$ oscillations in hepatocytes. The question of how $\mathrm{Ca}^{2+}$ waves propagate across a hepatocyte, which has previously been attributed to a wave of CICR traversing the cell, initiated by a focal rise in free $\mathrm{Ca}$ induced by local Ins $P_{3}$ generation [21], needs to be reconsidered. The most likely mechanism for generating phenylephrine-induced $\mathrm{Ca}^{2+}$ spikes in hepatocytes resides in the Ins $P_{: 3}$ pathway, either by pulsatile generation of Ins $P_{3}$, as we have previously favoured [2-5], or by complex dynamic behaviour of the $\operatorname{Ins} P_{3}$ receptor that we have outlined in the preceding paper [16]. In the latter model free $\mathrm{Ca}$ can promote, and then suppress, Ins $P_{3}$-receptor action; conceivably this feedback of free $\mathrm{Ca}$ on to the $\operatorname{Ins} P_{3}$ receptor could be responsible for $\mathrm{Ca}^{2+}$ waves, provided that the Ins $P_{3}$ is generated globally, not locally. Thus CICR mediated by the Ins $P_{3}$ receptor, rather than the ryanodine receptor, probably accounts for the phenylephrine-induced spikes.

If we accept that phenylephrine generates spikes solely by an Ins $P_{3}$-mediated mechanism, the problem then arises of why ryanodine abolishes vasopressin-induced or angiotensin IIinduced hepatocyte free $\mathrm{Ca}$ oscillations (Figures 2 and $3 \mathrm{~b}$ ), since both vasoactive peptides are, like phenylephrine, classical hepatocyte agonists for activating the phosphoinositide signalling pathway. The data kindly provided by L. L. T. Dasso and C. W. Taylor (unpublished work) indicate that ryanodine has no effect on vasopressin or phenylephrine binding to their receptors, nor on coupling to their G-protein(s). Evidence from this group also points to hepatocyte vasopressin and $\alpha_{1}$-adrenoreceptors sharing a common pool of G-proteins [20]. It is therefore most unlikely that ryanodine blocks phosphoinositidase $\mathrm{C}$ activation by vasopressin.

Unfortunately detailed information on the characteristics of the liver ryanodine receptor is, as yet, sparse. In other nonmuscle cells, ryanodine receptors have been shown to differ from that in muscle by being insensitive to caffeine and Ruthenium Red, or even to ryanodine. In liver, Shoshan-Barmatz et al. [15] show ryanodine binding to be $\mathrm{Ca}^{2+}$-insensitive, from which one would predict that the liver ryanodine receptor may not be capable of generating CICR. We can therefore only speculate on the possible mechanism of action of vasopressin-induced $\mathrm{Ca}^{2+}$ spiking. Differential localization of ryanodine and Ins $P_{3}$ receptors has been observed [15], and the concept of there being discrete Ins $P_{3}$-sensitive and -insensitive $\mathrm{Ca}^{2+}$ pools is widely recognized $[22,23]$. If a putative ryanodine-receptor-rich compartment, devoid of.Ins $P_{3}$ receptors, became $\mathrm{Ca}^{2+}$-loaded only in the presence of vasopressin, some of the effects of ryanodine described here would be explained. But, unless the ryanodine-receptor-rich pool were somehow to deplete the Ins $P_{3}$-receptor-rich compartment of 
its $\mathrm{Ca}^{2+}$ (but only when vasopressin was present), the ability of ryanodine to abolish the Ins $P_{3}$ component of the spikes would not be explained. Perhaps vasopressin generates a second messenger that links the lumen of an Ins $P_{3}$-receptor-rich compartment with a ryanodine-receptor-rich compartment? Alternative explanations also require an additional second messenger. For instance, does vasopressin somehow unmask ryanodine receptors that are inactive (or ryanodine- or $\mathrm{Ca}^{2+}$-insensitive) in unstimulated cells or in phenylephrine-stimulated cells? Is there a second messenger from vasopressin that causes $\mathrm{Ca}^{2+}$ to load into a ryanodine-receptor-rich compartment that is otherwise devoid of releasable $\mathrm{Ca}^{2+}$ ?

Whatever the nature of an additional second messenger involved in vasopressin signalling, it is clear that it has no effect on the rising phase of the spikes nor on $\mathrm{Ca}^{2+}$-wave propagation; this phase of the oscillator is probably solely the role of $\operatorname{Ins} P_{3}$ action. The putative second messenger would only be active during the falling phase of the spikes. Indeed, its action may be triggered by the rise in free $\mathrm{Ca}$ induced by Ins $P_{3}$ action. So a novel $\mathrm{Ca}^{2+}$-mobilizing second messenger acting independently of Ins $P_{3}$, for which cyclic ADP-ribose might provide a model [24], would be unlikely to explain our data. The effects of elevated cyclic AMP on spikes induced by phenylephrine and vasopressin are different [16], with prolonged falling phases appearing in the presence of vasopressin. The ability of ryanodine promptly to truncate their prolonged tails (Figure $3 b$ ) suggests some involvement of ryanodine receptors. These conditions, using either phenylephrine or vasopressin in the presence of elevated cyclic AMP, could be particularly useful in the search for the putative novel second messenger involved in this agonist-specific sensitivity of the hepatocyte $\mathrm{Ca}^{2+}$ oscillator to ryanodine.

We are grateful for funding by the Basque Country Government (A.S.-B.) and The Wellcome Trust.

\section{REFERENCES}

1 Woods, N. M., Cuthbertson, K. S. R. and Cobbold, P. H. (1986) Nature (London) 319, $600-602$

2 Woods, N. M., Cuthbertson, K. S. R. and Cobbold, P. H. (1987) Cell Calcium 8, $79-100$

3 Cobbold, P. H., Dixon, C. J., Sanchez-Bueno, A., Woods, N. M., Daly, M. and Cuthbertson, K. S. R. (1990) in Transmembrane Signalling: Intracellular Messengers and Implications for Drug Development (Nahorski, S. R., ed.), pp. 185-206, Wiley, Chichester

4 Sanchez-Bueno, A., Dixon, C. J., Woods, N. M., Cuthbertson, K. S. R. and Cobbold, P. H. (1990) Adv. Second Messenger Phosphoprotein Res. 24, 115-121

5 Cobbold, P. H., Sanchez-Bueno, A. and Dixon, C. J. (1991) Cell Calcium 12, 87-96

6 Joseph, S. K. and Williamson, J. R. (1986) J. Biol. Chem. 261, 14658-14664

7 Thomas, A. P. (1988) J. Biol. Chem. 263, 2704-2711

8 Fleischer, S., Ogunburmi, E. M., Dixon, M. C. and Fleer, E. A. M. (1985) Proc. Natl. Acad. Sci. U.S.A. 82, 7256-7259

9 lino, M., Kobayashi, T. and Endo, M. (1988) Biochem. Biophys. Res. Commun. 152, $417-422$

10 Ma, J., Fill, M., Knudson, C. M., Campbell, K. P. and Coronado, R. (1988) Science 242, 99-102

11 Malgaroli, A., Fesce, R. and Meldolesi, J. (1990) J. Biol. Chem. 265, 3005-3008

12 Foskett, J. K. and Wong, D. (1990) J. Cell Biol. 111, 466a

13 Meldolesi, J., Madeddu, L. and Pozzan, T. (1990) Biochim. Biophys. Acta 1055, $130-140$

14 Shoshan-Barmatz, V. (1990) FEBS Lett. 263, 317-320

15 Shoshan-Barmatz, V., Zhang, G. H., Garretson, L. and Kraus-Friedmann, N. (1990) Biochem. J. 268, 699-705

16 Sanchez-Bueno, A., Marrero, I. and Cobbold, P. H. (1993) Biochem. J. 291, 163-168

17 Sanchez-Bueno, A., Dixon, C. J., Woods, N. M., Cuthbertson, K. S. R. and Cobbold, P. H. (1990) Biochem. J. 268, 627-632

18 Somogyi, R. and Stucki, J. W. (1991) J. Biol. Chem. 266, 11068-11077

19 Dasso, L. L. T. and Taylor, C. W. (1991) Biochem. J. 280, 791-795

20 Dasso, L. L. T. and Taylor, C. W. (1992) Mol. Pharmacol. 42, 453-457

21 Rooney, T. A., Sass, E. J. and Thomas, A. P. (1990) J. Biol. Chem. 265, 10792-10796

22 Berridge, M. J., Cobbold, P. H. and Cuthbertson, K. S. R. (1988) Philos. Trans. R. Soc. London B 320, 325-343

23 Berridge, M. J. (1990) J. Biol. Chem. 265, 9583-9586

24 Galione, A., Lee, H. C. and Busa, W. B. (1991) Science 253, 1143-1146 